\title{
O DEPÓSITO DE NÍQUEL DE JACUPIRANGA (SP): EVOLUÇÃO MINERALÓGICA E GEOQUÍMICA
}

\author{
SONIA MARIA BARROS DE OLIVEIRA* e JEAN-JACQUES TRESCASES**
}

\begin{abstract}
The nickel deposit of Jacupiranga was formed by lateritic weathering of ultramafic rocks. The estimated reserves are $13 \mathrm{~m}$. ton, $1.4 \% \mathrm{Ni}$. The alteration profile is very thick and consists from bottom to top: a) fresh rock: serpentinized dunite; b) altered rock and argillaceous saprolite: serpentine and smectite, 30 to $40 \mathrm{~m}$ thick; c) silicified ferruginous saprolite: quartz and goethite, up to $25 \mathrm{~m}$ thick; d) upper horizon: kaolinite and goethite, up to $10 \mathrm{~m}$ thick. The weathering evolution of the serpentinized dunite has led to a loss of $\mathrm{Si}$ and $\mathrm{Mg}$ and a relative accumulation of $\mathrm{Fe}$ and $\mathrm{Al}$. In the silicified horizon absolute accumulation has occurred. The upper horizon seems to be only partially derived from the evolution of the dunite (too high content of Al). Nickel is mainly concentrated in the altered rock and in the argillaceous saprolite associated with serpentine and smectite. Furthermore it occurs as pimelite in the garnieritic veins that cut the altered rock. The content of $\mathrm{Ni}$ in these horizons ranges between $0.5 \%$ and $2 \%$ (up to $9 \%$ locally). In the ferruginous saprolite there is always less $\mathrm{Ni}(<1 \%)$, probably associated with geothite. Three factors make difficult the exploitation of the ore deposit: a) the thick overburden; b) the irregularity of the Ni distribution; c) the high silica content of the ore.
\end{abstract}

INTRODUÇÃo Conhecido desde os fins do século passado (Bauer 1890, Derby 1891), o distrito de Jacupiranga é um dos muitos maciços alcalinos situados ao redor da Bacia do Paraná. Situa-se a pouco mais de $200 \mathrm{~km}$ a sudoeste de São Paulo e a $10 \mathrm{~km}$ a oeste da cidade de Jacupiranga (Fig. 1). Submetido à alteração intempérica, desenvolveu uma espessa camada laterítica que comporta níveis enriquecidos em níquel. Foi em Jacupiranga que minerais supérgenos de níquel foram descritos pela primeira vez no Brasil (Felicíssimo 1968). As pesquisas iniciaram-se mais tarde, principalmente a partir de 1954, e até hoje os resultados não são inteiramente conclusivos quanto à economicidade do depósito. As reservas estimadas são da ordem de 13 milhões de toneladas a $1,4 \% \mathrm{Ni}$ (Morgental et al. 1975).

O clima atual da região (Ramalho \& Hansen 1975) é quente e úmido, com temperatura média anual de $21^{\circ} \mathrm{C}$ (médias mensais entre $17^{\circ} \mathrm{C} \mathrm{e} 25^{\circ} \mathrm{C}$ ). A pluviosidade situa-se ao redor de $1.500 \mathrm{~mm} / \mathrm{ano}$, bem distribuídos, mas ligeiramente mais concentrados nos meses de verão. A evapotranspiração, em torno de $1.000 \mathrm{~mm} / \mathrm{ano}$, assegura que não haja déficit de água. As condições climáticas atuais são, portanto, bastante favoráveis à laterização, que, quando ocorre sobre rochas ultrabásicas, como é o caso de parte do maciço de Jacupiranga, pode levar à concentração de níquel (Lelong et al. 1976). No centro-oeste brasileiro, sob condições climáticas de umidade menos permanente, um maciço ultramáfico-alcalino comparável ao de Jacupiranga (Santa Fé, GO) é portador de jazida de níquel (Oliveira $\&$ Trescases 1980).

O objetivo deste trabalho é o de reconhecer a seqüência evolutiva da alteração meteórica das rochas ultrabásicas de Jacupiranga e o de estabelecer uma hipótese explicativa para o baixo grau de concentração de níquel nas lateritas.

\section{QUADRO GEOLOGICO E GEOMORFOLÓGICO O}

maciço alcalino de Jacupiranga pertence à província alcalina do mesmo nome, que engloba também os maciços de Ipanema, Itanhaém e Juquiá, caracterizados pela presença de carbonatito e pelas idades em torno de $130 \mathrm{Ma}$ (Ulbrich \& Gomes 1981). Na classificação de Almeida (1983), Jacupiranga pertence à Província do Arco de Ponta Grossa, estando relacionado ao Alinhamento Estrutural de Guapiara.

Trata-se de um maciço de forma ovalada, com o eixo maior disposto na direção N-NW, perfazendo área de 65 $\mathrm{km}^{2}$ (Fig. 1). Intrusivo em rochas pré-cambrianas, encontrase encaixado, em sua porção sul, nos micaxistos do Grupo Açungui e, em sua porção norte, está em contato com rochas graníticas pertencentes ao Complexo GnáissicoMigmatítico (Morgental et al. 1975).

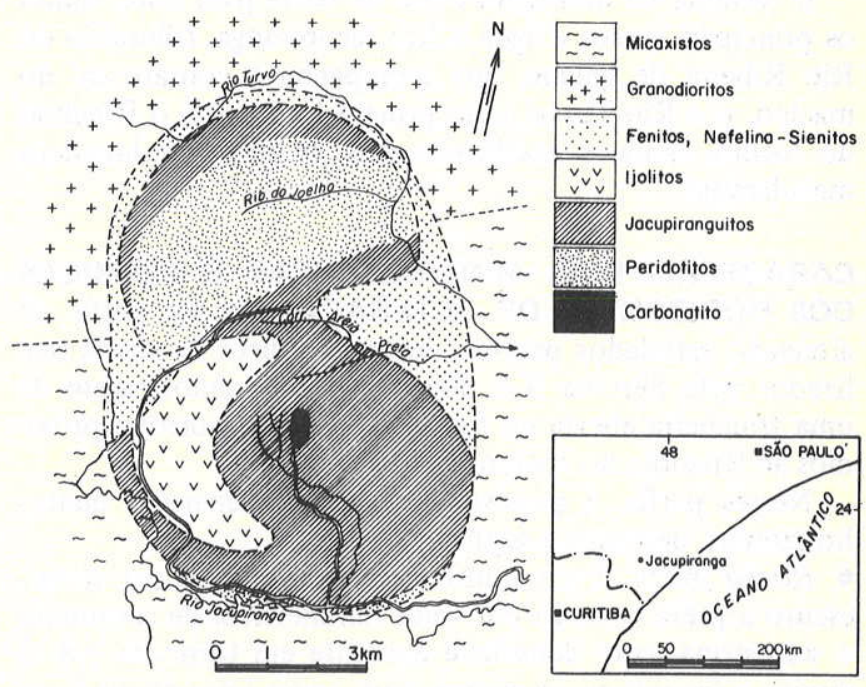

Figura 1 - Mapa de situação e esboço geológico ao macı̧̧o de Jacupiranga (Melcher 1954, modificado)

Segundo Melcher (1954), na porção meridional do maciço afloram jacupiranguitos (rochas compostas por titanoaugita e magnetita) que passam gradualmente a oeste para ijolitos (rochas compostas por nefelina e titano-augita), aflorantes em forma de lua minguante. A metade seten- 
trional do maciço é dominada por peridotitos. Nas bordas $\mathrm{NW}, \mathrm{N}$ e NE encontram-se rochas afetadas por fenitização. Um pequeno corpo de carbonatito tipo sövito (constituído por calcita e apatita) ocorre um pouco a sul do centro do maciço. Outras variedades de rochas alcalinas como monchiquito, tinguaíto, nefelinito, essexito e teralito estão presentes localmente sob a forma de diques.

As rochas peridotíticas, principal objeto deste trabalho, ocorrem numa área de mais ou menos $20 \mathrm{~km}^{2}$ e são predominantemente duníticas, passando, em direção às bordas do corpo, para termos mais piroxeníticos. Apresentam-se afetadas por intemperismo que transformou grande parte das olivinas em minerais do grupo das serpentinas. Veios carbonáticos recortam o dunito serpentinizado e devem ter sua origem relacionada a este mesmo processo.

O maciço ocupa um compartimento do relevo pertencente à Província Costeira denominado Morraria Costeira (Ponçano et al. 1981). Corresponde a uma extensa zona de relevos arrasados, constituída por morrotes e colinas de altitudes que variam entre 40 e $300 \mathrm{~m}$. É a área de transição entre a Serrania Costeira (altitudes de 800 a $1.000 \mathrm{~m}$ ) e a Baixada Litorânea.

$\mathrm{Na}$ porção sul do maciço, os jacupiranguitos constituem as porções mais baixas do relevo (altitudes em torno de 15-50 m). Funcionando como divisor de águas entre os Rios Jacupiranga e Turvo, ocorre uma zona de morros, dos quais os mais elevados estão esculpidos em carbonatito (200 m) e ijolito (mais de $300 \mathrm{~m}$ ).

$\mathrm{Na}$ área dos peridotitos, distingue-se a leste uma região de morrotes meia-laranja e altitudes máximas de $150 \mathrm{~m}$ e a oeste um platô menos dissecado (altitudes em redor de $190 \mathrm{~m}$ ). O setor notre encontra-se mais erodido, com cotas na faixa de $120-180 \mathrm{~m}$.

O sistema de drenagem corre de oeste para leste, sendo os principais cursos d'água o Rio Jacupiranga, tributário do Rio Ribeira de Iguape, que acompanha o contato sul do maciço, e o Rio Turvo, cujo principal afluente, o Ribeirão do Joelho, drena os interflúvios entre os morrotes duníticos meia-laranja.

\section{CARACTERISTICAS MINERALOGICAS E QUIMIICAS DOS HORIZONTES DE ALTERAÇÃO Os perfis de} alteração estudados provêm de quatro furos de sonda realizados pela Serrana S.A. Mineração e da amostragem de uma trincheira aberta no flanco de um dos morrotes próximos ao Ribeirão do Joelho.

Nesses perfis, é possível distinguir basicamente quatro horizontes, descritos a seguir:

- Rocha fresca. É um dunito serpentinizado, de cor verdeescuro a preta cortado por veios milimétricos de carbonato e serpentina, com densidade aparente em torno de 2,8. 0 dunito apresenta-se ao microscópio como um reticulado de serpentina (60\%), cujos núcleos estão ocupados pelos restos da olivina que escaparam à serpentinização (40\%). Como acessórios, estão presentes principalmente cromita, magnetita e ilmenita. Este fácies só aparece nos furos de sondagem a profundidades superiores a $60 \mathrm{~m}$ e não aflora na base do perfil de trincheira.

- Rocha alterada, saprólito grosso e saprólito argiloso. Com o início da alteração, a rocha perde progressivamente a coesão, embora mantenha a estrutura conservada. A densidade aparente cai para intervalos da ordem de 1,5 a 2,5 e a coloração torna-se mais clara, com tons de amarelado ou esverdeado. $\mathrm{Na}$ base deste horizonte, a serpentina permanece e a olivina é substituída ou por um material ferruginoso marrom (mistura de esmectita e compostos ferruginosos) que começa por invadir suas descontinuidades e acaba por substituir todo o cristal - ou por um material argiloso esverdeado (esmectita). A serpentina, embora permaneça, assume uma coloração verde-amarelada típica das serpentinas enriquecidas em níquel (Oliveira \& Trescases 1980). Os carbonatos são dissolvidos, deixando espaços parcialmente preenchidos por material ferruginoso marrom. Com o avanço da alteração, a textura da rocha torna-se progressivamente irreconhecível ao microscópio, sendo tudo rapidamente transformado em material esmectítico; a nível de afloramento, no entanto, a estrutura permanece grosseiramente conservada. Ao estágio intermediário entre a rocha alterada e o saprólito argiloso deu-se o nome de saprólito grosso. Bolsőes de material clorítico, provavelmente herdados da rocha sã e ligeiramente evoluídos em esmectita, ocorrem heterogeneamente distribuídos e aparentemente não perturbados dentro do nível saprolítico. Veios de quartzo, serpentina niquelífera e pimelita cortam este horizonte, principalmente em sua porção basal. No topo, são comuns concreções pretas de asbolano. $\mathrm{O}$ horizonte como um todo atinge espessuras de 30 a $40 \mathrm{~m}$, sendo a parte argilosa, em geral, reduzida a poucos metros.

- Saprólito ferruginoso silicificado. É um horizonte muito heterogêneo, podendo ser concebido como uma mistura, em proporções variadas, de um pólo quartzoso e de um pólo goethítico. A estrutura é de um boxwork silicoso com material goethítico avermelhado, exibindo ainda ao microscópio vestígios da estrutura original em seus núcleos. Quando o pólo quartzoso domina, as densidades são mais elevadas, da ordem de 2; se o que predomina é o saprólito ferruginoso, a densidade pode cair até valores próximos de 1 . Atinge, nos topos dos platôs, espessuras de até $30 \mathrm{~m}$, diminuindo sensivelmente nas encostas e talvegues.

- Material de cobertura. Horizonte que capeia os perfis, com espessura da ordem de $10 \mathrm{~m}$, podendo encontrar-se ausente nas encostas mais erodidas. E um material pulverulento, de cor marrom-avermelhada com tons violáceos, sem nenhum vestígio de estrutura litológica. Sua constituição mineralógica é essencialmente caulinita e goethita, contendo também um pouco de quartzo.

A rocha fresca pode, algumas vezes, ser atravessada por veios de feldspato alcalino, relacionados provavelmente às fases finais da intrusão. Com a alteração, ao longo das clivagens do feldspato, instala-se esmectita niquelífera, o que dá cor esverdeada ao mineral. Feldspatos niquelíferos semelhantes a estes foram descritos por Melfi et al. (1970) em Niquelândia.

Evolução Mineralógica Os primeiros minerais a se alterar são a olivina e os carbonatos. A hidrólise da olivina é incongruente e deixa como resíduo argilas esmectíticas ricas em $\mathrm{Mg}, \mathrm{Fe}$ e $\mathrm{Ni}$, sempre misturadas com quantidades variáveis de goethita. Parte da sílica liberada cristaliza-se sob a forma de quartzo ou associa-se ao $\mathrm{Mg}$ e ao Ni na pimelita e na serpentina niquelífera (garnieritas: Brindley 1978). Com o avanço da alteração, a esmectita desestabiliza-se e deixa um resíduo ferruginoso de composição goethítica. $O$ quartzo neoformado permanece até os níveis mais alterados, mas as garnieritas se dissolvem precocemente. Os carbonatos sofrem dissolução congruente. 
O primeiro sinal de alteração da serpentina é a mudança da cor, de incolor para verde-amarelada. Neste estágio. a serpentina constitui uma excelente armadilha para o Ni. A difração de raios-X, contudo, não revela nenhuma modificação. A serpentina alterada vai desaparecendo progressivamente do perfil sem que tenha sido possível determinar se ela também origina esmectita ou se simplesmente se dissolve, deixando um escasso resíduo goethítico.

Composição química de cada horizonte A tabela 1 mostra a composição química média dos vários horizontes do perfil de alteração.

Tabela 1 - Valores médios (\% em peso) dos principais óxidos nos diferentes horizontes. $R F$ : rocha fresca; $R A$ : rocha alterada; $\mathrm{SA}$ : saprolito argiloso; $\mathrm{SF}+\mathrm{SiO}_{2}$ : saprolito ferruginoso silicificado

\begin{tabular}{c|c|c|c|c|c|c|c|c|c|c}
\hline & $\mathrm{PF}$ & $\mathrm{SiO}_{2}$ & $\mathrm{MgO}_{8}$ & $\mathrm{Fe}_{2} \mathrm{O}_{3}$ & $\mathrm{Al}_{2} \mathrm{O}_{3}$ & $\mathrm{Cr}_{2} \mathrm{O}_{3}$ & $\mathrm{MnO}_{2}$ & $\mathrm{NiO}$ & $\mathrm{CoO}$ & $\mathrm{Cuo}$ \\
\hline $\begin{array}{c}\text { Material } \\
\text { de } \\
\text { Cobertura }\end{array}$ & $10-13$ & $20-40$ & $0,2-0,3$ & $25-40$ & $15-25$ & $0,7-2,0$ & $0,1-0,2$ & $0,1-0,2$ & $0-0,05$ & 0,010 \\
\hline $\mathrm{SF}+\mathrm{SiO}_{2}$ & $2-11$ & $11-87$ & $0,3-0,8$ & $7-70$ & $0,5-3$ & $0,3-2,8$ & $0,1-0,4$ & $0,05-1,0$ & 0,003 & 0,008 \\
\hline $\mathrm{SA}$ & $8-10$ & $30-60$ & $5-20$ & $18-30$ & $0,3-1,5$ & $1,0-1,5$ & $0,3-0,7$ & $0,4-1,5$ & 0,04 & 0,004 \\
\hline $\mathrm{RA}$ & $10-12$ & $40-50$ & $15-35$ & $13-20$ & $0,4-0,6$ & $1-1,5$ & $0,3-0,7$ & $0,4-2,0$ & 0,03 & 0,004 \\
\hline $\mathrm{RF}$ & 9 & 40 & 37 & 10 & 0,2 & 0,4 & 0,3 & 0,3 & 0,02 & 0,005 \\
\hline
\end{tabular}

A rocha fresca apresenta composição química típica de dunitos serpentinizados, com altos valores de $\mathrm{MgO}$ e baixos teores de $\mathrm{Al}_{2} \mathrm{O}_{3}$. A perda ao fogo elevada é devida à presença de serpentina. O teor de $\mathrm{NiO}$, em torno de $0,3 \%$, também corresponde aos valores comumente encontrados neste tipo de rochas. $\mathrm{O}$ teor de cobre é baixo, o que é comum nas rochas ultramáficas de filiação alcalina.

$\mathrm{Na}$ rocha alterada, a maior diferença em relação à rocha fresca é a queda nos teores de $\mathrm{MgO}$, o que corresponde à hidrólise de olivina. Os elementos de comportamento marcadamente residual ( $\mathrm{Fe}, \mathrm{Al}, \mathrm{Cr}$ ) sofrem significativa elevação de teor. Quanto ao $\mathrm{Ni}$, a grande faixa de variação apresentada na tabela (de $0,4 \%$ a 2,0\%) deve-se à heterogeneidade em sua distribuição: a rocha alterada pode estar mais ou menos recortada por veios garnieríticos. Na ausência dos veios de garnierita, a rocha dura apresenta teores de $\mathrm{NiO}$ muito baixos $(<0,5 \%$ em geral).

A composição química do saprólito argiloso indica que a esmectita, mineral dominante neste horizonte, deve ser de natureza magnesiana e ferrífera com um pouco de níquel. Este nível é o que apresenta maiores concentrações de $\mathrm{Mn}$ e $\mathrm{Co}$, correspondentes às concreções de asbolano. $\mathrm{O}$ níquel também varia muito (de 0,4 a $1,5 \% \mathrm{NiO}$ ), sendo os maiores teores encontrados nos bolsões argilosos de cloritaesmectita (até 3\% $\mathrm{NiO}$ ).

Quando o nível de saprólito ferruginoso silicificado é dominado pelo pólo quartzoso, a análise química mostra elevados teores em $\mathrm{SiO}_{2}$, baixa perda ao fogo e teores de $\mathrm{Ni}$ baixíssimos $(<0,1 \% \mathrm{NiO})$. $\mathrm{Se}$, ao contrário, é o pólo ferruginoso que predomina, a perda ao fogo é mais alta e o níquel pode estar presente em quantidades mais elevadas, não superando geralmente o valor de $1 \%$. Neste caso, associa-se provavelmente à goethita.

O material de cobertura apresenta uma composição quí- mica muito diferente: teores de $\mathrm{Al}$ muito elevados e de $\mathrm{Cr}$, $\mathrm{Mn}, \mathrm{Ni}$ e Co mais baixos.

Admitindo o $\mathrm{Fe}_{2} \mathrm{O}_{3}$ como óxido de referência, por ser, entre os mais abundantes, o menos móvel, foram calculadas as razões $\mathrm{SiO}_{2} / \mathrm{Fe}_{2} \mathrm{O}_{3}, \mathrm{MgO} / \mathrm{Fe}_{2} \mathrm{O}_{3}, \mathrm{Al}_{2} \mathrm{O}_{3} / \mathrm{Fe}_{2} \mathrm{O}_{3}$, $\mathrm{Cr}_{2} \mathrm{O}_{3} / \mathrm{Fe}_{2} \mathrm{O}_{3}$ e $\mathrm{NiO} / \mathrm{Fe}_{2} \mathrm{O}_{3}$ com a finalidade de examinar o comportamento desses óxidos no decorrer da alteração (Tab. 2).

Tabela 2 - Intervalos de variação das razões $\mathrm{SiO}_{2}, \mathrm{MgO}$, $\mathrm{Al}_{2} \mathrm{O}_{3}, \mathrm{Cr}_{2} \mathrm{O}_{3}$ e $\mathrm{NiO}$ em relação ao $\mathrm{Fe}_{2} \mathrm{O}_{3}$, nos vários horizontes de alteração

\begin{tabular}{c|c|c|c|c|c}
\hline & $\frac{\mathrm{SiO}_{2}}{\mathrm{Fe}_{2} \mathrm{O}_{3}}$ & $\frac{\mathrm{MgO}}{\mathrm{Fe}_{2} \mathrm{O}_{3}}$ & $\frac{\mathrm{Al}_{2} \mathrm{O}_{3}}{\mathrm{Fe}_{2} \mathrm{O}_{3}}$ & $\frac{\mathrm{Cr}_{2} \mathrm{O}_{3}}{\mathrm{Fe}_{2} \mathrm{O}_{3}}$ & $\frac{\mathrm{NiO}}{\mathrm{Fe}_{2} \mathrm{O}_{3}}$ \\
\hline $\begin{array}{c}\text { Material } \\
\text { de } \\
\text { Cobertura }\end{array}$ & $0,8-1,6$ & 0,0 & $0,5-0,8$ & $0,02-0,06$ & $0,002-0,005$ \\
\hline $\mathrm{SF}+\mathrm{SiO}_{2}$ & $0,2-12,2$ & 0,0 & $0,03-0,07$ & $0,04-0,07$ & $0,008-0,044$ \\
\hline $\mathrm{SA} / \mathrm{RA}$ & $2,4-4,1$ & $0,9-2,2$ & $0,02-0,08$ & $0,04-0,10$ & $0,018-0,211$ \\
\hline $\mathrm{RF}$ & 4,0 & 3,6 & 0,02 & 0,04 & 0,028 \\
\hline
\end{tabular}

Para a seqüência rocha fresca-saprólito ferruginoso silicificado foram observadas as seguintes tendências: $\mathrm{SiO}_{2} /$ $\mathrm{Fe}_{2} \mathrm{O}_{3}$ de maneira geral decresce, salvo em níveis muito silicificados; $\mathrm{MgO} / \mathrm{Fe}_{2} \mathrm{O}_{3}$ tende a zero; $\mathrm{Al}_{2} \mathrm{O}_{3} / \mathrm{Fe}_{2} \mathrm{O}_{3}$ e $\mathrm{Cr}_{2} \mathrm{O}_{3} / \mathrm{Fe}_{2} \mathrm{O}_{3}$ permanecem constantes ou aumentam ligeiramente; e $\mathrm{NiO} / \mathrm{Fe}_{2} \mathrm{O}_{3}$ varia numa ampla faixa atingindo valores quase 10 vezes mais elevados que na rocha fresca no horizonte de rocha alterada. Fica, portanto, caracterizado uma evolução laterítica, com perda parcial de $\mathrm{SiO}_{2}$, intensa de $\mathrm{Mg}$ e aproximada conservação de $\mathrm{Fe}, \mathrm{Al}$ e $\mathrm{Cr}$. $\mathrm{O} \mathrm{Ni}$, de comportamento mais irregular, encontra-se ora lixiviado, ora concentrado. No material de cobertura, as razões $\mathrm{Al}_{2} \mathrm{O}_{3} / \mathrm{Fe}_{2} \mathrm{O}_{3}$ e $\mathrm{NiO} / \mathrm{Fe}_{2} \mathrm{O}_{3}$ situam-se numa faixa de valores incompatível com uma derivação dunítica. $\mathrm{O}$ caráter alóctone dessa cobertura, pelo menos parcial, fica, assim, demonstrado.

A figura 2 mostra um diagrama dos teores de Ni em função dos teores de $\mathrm{MgO}$, dosados para algumas amostras (supostamente de minério) retiradas das trincheiras abertas nas colinas da área do Ribeirão do Joelho. A correlação positiva entre esses dois elementos na faixa de teores de $\mathrm{MgO}$ abaixo de $20 \%$ parece bem estabelecida e indica que a progressiva destruição da serpentina e, posteriormente, da esmectita se dá com perda de níquel.

Composição química das frações granulométricas No intuito de precisar melhor o comportamento de certos elementos e sua relação com as fases presentes, foram efetuadas análises químicas de quatro frações granulométricas (A > $2 \mathrm{~mm} ; 2 \mathrm{~mm}>\mathrm{B}>210 \mu \mathrm{m} ; 210 \mu \mathrm{m}>\mathrm{C}>74 \mu \mathrm{m}$; $\mathrm{D}<74 \mu \mathrm{m})$ para amostras provenientes de diferentes níveis de alteração. Os resultados estão apresentados na Tabela 3 .

Na rocha alterada (amostra IV), a fração mais fina, embora predominante, representa menos da metade da amostra. A composição química de todas as frações de tamanho abaixo de $2 \mathrm{~mm}$ (B, C e D) é bastante parecida, sendo todas 


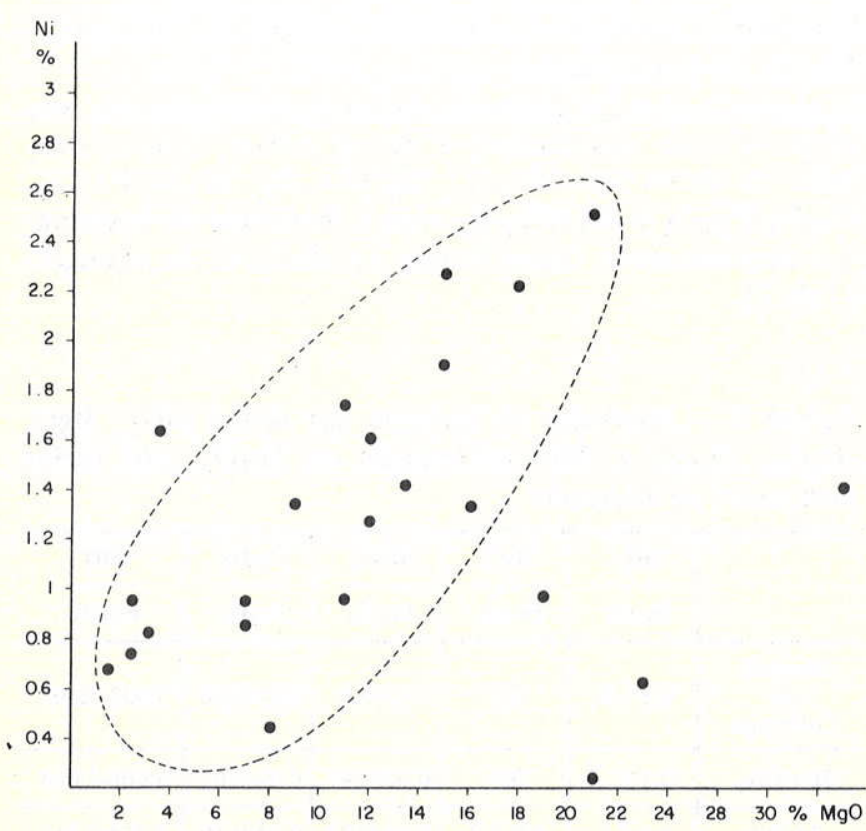

Figura 2 - Diagrama de correlação $\mathrm{MgO} \times \mathrm{Ni}$ para amostras de minério proveniente das trincheiras da região do Ribeirão do Joelho

Tabela 3 - Composição química das frações granulométricas para os horizontes, I, II, III e IV. Frações $A>2 \mathrm{~mm}$; $2 \mathrm{~mm}>B>210 \mu \mathrm{m} ; 210 \mu \mathrm{m}>C>74 \mu \mathrm{m} ; D>74 \mu \mathrm{m}$

\begin{tabular}{|c|c|c|c|c|c|c|c|c|c|c|c|}
\hline & & PF & $\mathrm{SiO}_{2}$ & $\mathrm{MgO}$ & $\mathrm{Fe}_{2} \mathrm{O}_{3}$ & $\mathrm{Al}_{2} \mathrm{O}_{3}$ & $\mathrm{Cr}_{2} \mathrm{O}_{3}$ & $\mathrm{MnO}_{2}$ & NiO & $\mathrm{CoO}$ & $\mathrm{CuO}$ \\
\hline & $(0,2)^{*}$ & 7,4 & 34,3 & 0,11 & 5 & 1 & 1,50 & 25 & 3 & 0,018 & 0,205 \\
\hline & B $(8,6)$ & 11,1 & 64 & 0,33 & 27,9 & 20,0 & 2,80 & 0,17 & 0,09 & 006 & 023 \\
\hline & C $(9,3)$ & 10,6 & 37 & & 2 & 19,7 & & & & 008 & 03 \\
\hline & D $(81,9$ & 1 & 35,1 & 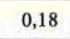 & 27 & 22,0 & 0,85 & 0,13 & 0 & 004 &, 013 \\
\hline & A $(10$, & 1,0 & 94 & 0,17 & & & & & &, 028 &, 00 \\
\hline & B $(24$, & 4 , & 71 & 0 , & 13 & 4,2 & 1 & 2,25 & 0,68 & 0,245 & 0,0 \\
\hline & C $(1,2,7)$ & 6,5 & 21,2 & 2,90 & 488 & 106 & 8 & 1 & 1 & 2 & 0,022 \\
\hline & $\mathrm{D}(52,2$ & 10 & 22,6 & 1,9 & 49,2 & 1 & 1 , & 0,6 & 1,3 & 0,048 & 0,014 \\
\hline \multirow{4}{*}{ III } & A $\quad(1,2$ & 10,5 & 60 & 3.5 & 63 & 13 & 0,57 & 0,31 & 0,69 & 0,028 & 0,059 \\
\hline & B (18, & 10,2 & 3 & 3,98 & 37,5 & 3,1 & 2,0 & 2,31 & 1,94 & 0,253 & 0,013 \\
\hline & C $(19,9)$ & 7,5 & 28,5 & 4,02 & 44 & 4 & 6 & 1,26 & 1,77 & 0,108 & 0,028 \\
\hline & $\mathrm{D}(60,5)$ & 11,0 & 33,5 & 3,90 & 40,2 & 5 , & 1,2 & 085 & 2,38 & 0,069 & 0,02 \\
\hline & 7 & 7,0 & 6 & 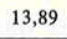 & & 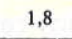 & 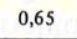 & 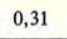 & 2,70 & 5 & 0,009 \\
\hline & B $(23$, & 11,4 & 47 & 18,65 & 13 & 0 & 06 & 0 & 3,7 & 0,040 & 0,008 \\
\hline & C $(9,3)$ & 8, & 43, & 15,13 & 23 & 2,0 & 1,5 & 0 & 3,24 & 0,042 & 0,043 \\
\hline & D & 9 & & 18,24 & 1 & 2 , & 0 & 0 , & 6 , & ,019 & 0 , \\
\hline
\end{tabular}

* Os números entre parênteses correspondem à porcentagem da fração na amostra.

elas constituídas principalmente por serpentina e esmectita (Al, Fe, Mg). O níquel, todavia, concentra-se um pouco mais na fração $\mathrm{D}$, mais fina, provavelmente associado à esmectita. A fração A, mais grossa, é a única a exibir presença de quartzo além de serpentina e contém um pouco menos de níquel. Os teores de cobalto e manganês mostram uma correlação estreita em todas as frações, evidenciando a estrita associação desses elementos nas concreções de asbolano, mais abundantes nas frações B e C. O cromo aparece melhor na fração $74-210 \mu \mathrm{m}$, que corresponde ao tamanho dos grãos de cromita.
A amostra III representa uma transição entre o saprólito argiloso e o saprólito ferruginoso silicificado. A fração fina predomina, representando mais de $60 \%$ das amostras. Como na amostra anterior, as frações $\mathrm{B}, \mathrm{C}$ e $\mathrm{D}$ não contêm quartzo e mostram análises parecidas. $\mathrm{O}$ quartzo está localizado na fração grossa, enquanto a fração fina está enriquecida em níquel. Mais nitidamente que na amostra anterior, as frações intermediárias concentram o asbolano (como é demonstrado pela permanência da correlação $\mathrm{Mn}-\mathrm{Co}$ ) e a cromita, embora o teor em $\mathrm{Cr}$ da fração fina evidencie o início da alteração dos grãos de cromita.

No saprólito ferruginoso silificado (II), o pólo quartzoso é representado pelas duas frações mais grossas, muito empobrecidas em níquel, e o pólo ferruginoso pelas duas mais finas, em que o níquel está mais concentrado, embora em teores muito menores que nas amostras anteriores. Mn e Co de um lado e $\mathrm{Cr}$ de outro têm o mesmo padrão de distribuição que nos horizontes menos alteradoș.

No horizonte de cobertura (I), com granulometria muito fina, as três frações de tamanho abaixo de $2 \mathrm{~mm}$ são compostas por quartzo, goethita e bastante caulinita enquanto na fração mais grossa, em que a caulinita é menos abundante, um concrecionamento ferruginoso incipiente é notado. Embora com teores menores que nos horizontes in situ do perfil, $\mathrm{Mn}$, Co e $\mathrm{Cr}$ distribuem-se da mesma maneira.

Um elemento mostra um comportamento bastante original, apesar de seus teores permanecerem baixos. É o cobre, nitidamente concentrado nas frações finas na base do perfil, junto com as esmectitas, e na fração grossa no topo, associado ao concrecionamento ferruginoso.

Balanço geoquímico da alteração $\mathrm{O}$ balanço geoquímico calculado para a transição rocha fresca-saprólito argiloso (Tab. 4) mostra que esta evolução se dá por perda intensa de $\mathrm{Mg}$, parcial de $\mathrm{Si}$ e concentração relativa de $\mathrm{Fe}$. Essa perda de massa, da ordem de $50 \%$, não é, isoladamente, suficiente para causar enriquecimento em níquel nos níveis encontrados neste horizonte (até 500\% localmente). Esses enriquecimentos locais são absolutos, mas muitas amostras apresentam apenas estrita conservação do níquel inicial e algumas delas mostram até perdas.

Tabela 4 - Balanço geoquímico (perdas e ganhos expressos em \%)

\begin{tabular}{lccccc}
\hline & Densid. & $\mathrm{SiO}_{2}$ & $\mathrm{MgO}$ & $\mathrm{Fe}_{2} \mathrm{O}_{3}$ & $\mathrm{Ni}$ \\
\hline $\mathrm{RF} \rightarrow \mathrm{SA}$ & -50 & -50 & -80 & 0 & $\begin{array}{l}0 \text { até } \\
+500 \%\end{array}$ \\
\hline $\mathrm{RF} \rightarrow$ POLO FERRUGINOSO & -70 & -80 & -99 & 0 & $\begin{array}{l}-50 \% \text { até } \\
+20 \%\end{array}$ \\
\hline $\mathrm{RF} \rightarrow$ POLO QUARTZOSO & -20 & +70 & -99 & -50 & $\begin{array}{l}-99 \% \text { até } \\
-80 \%\end{array}$ \\
\hline
\end{tabular}

No caso do saprólito ferruginoso silicificado, o pólo ferruginoso parece bem a continuação da tendência acima descrita: a perda de massa se acentua com eliminação total do $\mathrm{Mg}$ e da maior parte da sílica, permanecendo o Fe. O material pode ser descrito como uma verdadeira laterita que perdeu parte de seu conteúdo em níquel em favor dos níveis inferiores. No pólo silicificado, no entanto, nota-se uma tendência completamente diferente: a sílica não só não é eliminada, como também aumenta em valores absolutos, o que configura aporte. A exemplo de outras jazidas brasi- 
leiras, como Santa Fé, Niquelândia, São João do Piauí (Melfi et al. 1980), o nível silicificado deve corresponder à base de um antigo perfil elaborado em situação de lixiviação de sílica dificultada, pois atualmente, como vimos, a tendência é de eliminação de sílica. Esse horizonte de base antigo, constituído, portanto, por rocha pouco alterada muito silicificada, foi retomado pelo intemperismo subatual e deixou como resíduo um boxwork preenchido por material laterítico (pólo ferruginoso). O pólo quartzoso representa esse boxwork esvaziado da laterita, como mostra o balanço na tabela 4 (perda absoluta de $\mathrm{Fe}_{2} \mathrm{O}_{3}$ ).

0 material de cobertura não deve provir da mesma seqüência de alteração, isto é, deve ser material em parte alóctone, proveniente de rochas com elevado teor de $\mathrm{Al}$, como são os fenitos que circundam as áreas peridotíticas e os ijolitos situados mais a sul.

ESTRUTURA GERAL DA JAZIDA A figura 3 indica a localização das três topo-seqüências estudadas. As toposeqüências I e II estão na borda do platô, na parte ocidental do maciço; a topo-seqüência III atravessa a zona leste, onde a topografia é dominada pelos morrotes meia-laranja.
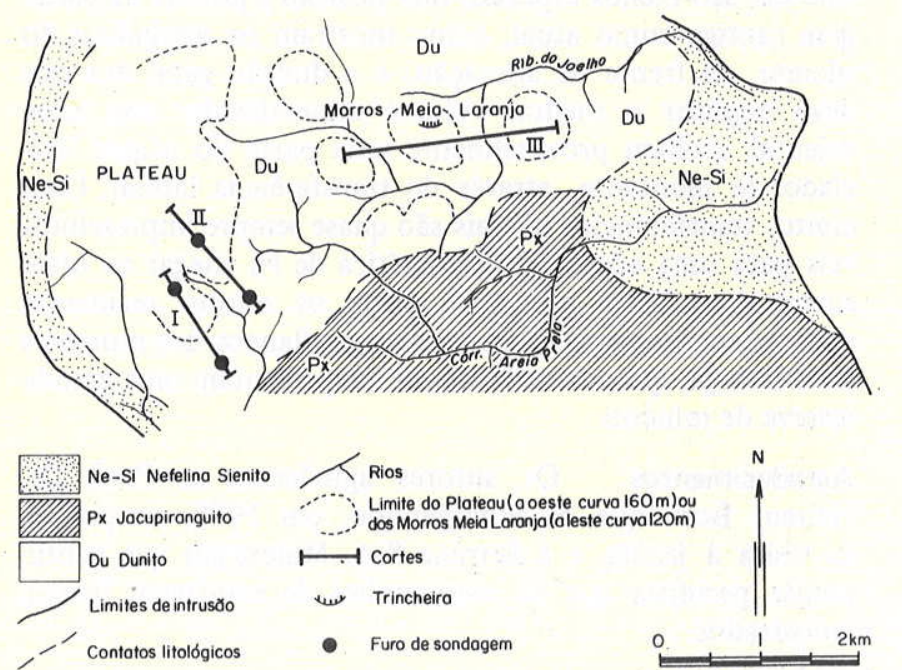

Figura 3 - Localização das 3 seções transversais estudadas

A figura 4 mostra a distribuição dos fácies de alteração ao longo das três topo-seqüências.

O horizonte de cobertura é espesso no platô e nos topos dos morrotes. Adelgaça-se bastante nas encostas e pode até estar ausente em sítios mais erodidos.

A espessura do horizonte silicoso varia muito, dependendo do local. É muito espesso na parte oeste, onde o platô é menos dissecado, e aparece com uma espessura menor nas encostas correspondentes à incisão do platô. $\mathrm{Na}$ parte leste, ele tem uma espessura geralmente menor e, como nas bordas do platô, adelgaça-se nas encostas muito íngremes dos morrotes meia-laranja. Parece que este nível tem um leve mergulho geral para leste ou sudeste e que sua espessura diminui na mesma direção.

Debaixo da camada silicosa, o perfil saprolítico é mais espesso nos lugares de topografia pouco inclinada (platô, topo dos morrotes) e menos desenvolvido nas encostas, onde os fácies argilosos chegam a desaparecer. Os teores de níquel e os volumes mineralizados parecem aumentar na direção leste, quer dizer, na direção geral do mergulho do nível silicificado, bem como, possivelmente, do contato rocha alterada-rocha fresca.
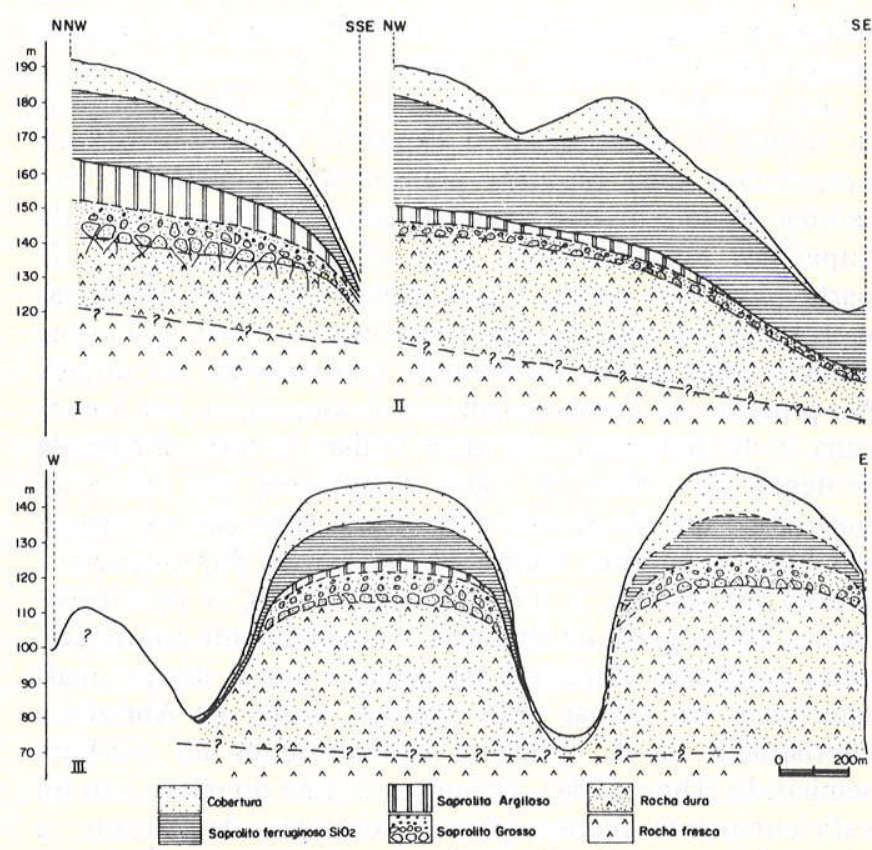

Figura 4 - Distribuição das fácies da alteração ao longo de 3 toposseqüências

INTERPRETAÇÃO GENÉTICA A comparação da jazida de Jacupiranga com as demais jazidas de níquel laterítico do Brasil pode fornecer hipóteses explicativas a respeito dos processos que intervieram na elaboração da concentração de níquel, e permitir uma avaliação do papel desempenhado pelos fatores climáticos e morfológicos neste processo.

Do ponto de vista geomorfológico, os maciços ultramáficos portadores de jazida laterítica de níquel aparecem de um modo geral no Brasil sob a forma de relevos tabulares (Melfi et al. 1980). Os pontos altos correspondem aos testemunhos de uma antiga superfície de aplainamento, a Superfície Sul-Americana (King 1956), de idade terciária inferior, e são sempre cobertos por uma camada de silcrete. Quando existe no maciço ultramáfico alguma zona de altitude menor que o topo tabular (na periferia ou sob a forma de uma baixada cavada no interior do maciço), esta correlaciona-se com uma superfície de aplainamento mais recente, denominada Superfície Velhas (King 1956) de idade terciária superior; nesta zona baixa não há silcrete, a cobertura é constituída por um horizonte ferruginoso pulverulento (laterita vermelha). O grau de dissecação da Superfície Sul-Americana e o desenvolvimento correlativo da Superfície Velhas são muito variáveis, dependendo do tamanho do maciço e de fatores tectônicos. Na parte peridotítica do maciço de Jacupiranga, o platô situado a oeste parece assemelhar-se aos relevos tabulares com silcrete atribuídos à Superfície Sul-Americana enquanto os morrotes meialaranja da zona leste poderiam constituir testemunhos da mesma superfície; neste maciço nenhuma baixada atinge tamanho significativo e não se pode falar de nível Velhas. Esse baixo grau de erosão faz com que o maciço de Jacupiranga, apesar de grande, seja mais parecido com os pequenos corpos ultramáficos (como Morro do Níquel, Trescases \& Oliveira 1978) do que com as ultramáfico-alcalinas de Goiás (como Santa Fé, Oliveira \& Trescases 1980). Essa conservação relativa da morfologia do Terciário poderia ser uma conseqüência da localização do maciço de Jacupiranga numa porção rebaixada (tectonicamente?) do relevo em 
relação ao planalto, que atinge de 800 a $1.000 \mathrm{~m}$ de altitude nessa região (falhamento da Superfície Sul-Americana? ).

Ao interpretar a evolução geral das jazidas lateríticas de níquel do Brasil desde o Terciário, Melfi et al. (1980) propuseram uma hipótese poligenética: a alteração meteórica ter-se-ia iniciado no Terciário inferior ao nível da Superfície Sul-Americana, com intensas silicificações da parte basal dos perfis, o que sugere condições climáticas mais secas; em seguida, uma longa fase de lateritização teria afetado estes perfis, provocando concentração do níquel. No processo de desmantelamento da Superfície Sul-Ämericana e de elaboração do nível Velhas, a zona silicificada protegeu da erosão os topos silicificados que aparecem hoje como um silcrete sub-aflorante. A alteração prosseguiu até hoje ao mesmo tempo na Superfície Sul-Americana, abaixo do silçrete, e na superfície Velhas. O desenvolvimento desses perfis de alteração foi estritamente controlado pelas condições climáticas sub-atuais a atuais: sempre mais lateríticos em climas mais úmidos, como na Amazônia (Bernardelli et al. 1983), e não-lateríticos no nordeste semi-árido (Dino 1984). Quando a incisão do relevo não foi suficientemente intensa para a formação de baixada, a alteração progrediu apenas debaixo do silcrete. É o caso de Jacupiranga, onde a camada silicosa é bastante espessa e localizada acima do perfil de alteração in situ. Este perfil, constituído principalmente por um nível de rocha pouco alterada, apresenta tendência à esmectização, o que poderia ser um reflexo da posição muito meridional de Jacupiranga, a sul do Trópico de Capricórnio. Em outras jazidas brasileiras, a evolução é mais rápida em direção a um nível de saprólito ferruginoso debaixo do silcrete, cada vez mais espesso à medida que o clima é mais quente e mais úmido. A originalidade da jazida de Jacupiranga está na grande espessura da cobertura laterítica vermelha acima do silcrete. Esta cobertura, embora não inteiramente de derivação dunítica, mostra teores de $\mathrm{Cr}$ e $\mathrm{Co}$, que indicam a participação de rochas ultrabásicas em sua elaboração. Assim, essa cobertura poderia representar em parte uma herança dos antigos perfis laterizados que cobriam a Superfície Sul-
Americana, perfis que foram erodidos nas outras jazidas devido ao maior grau de desmantelamento destas.

CONCLUSÕES Pode-se dizer que a jazida de Jacupiranga ocupa um lugar muito particular no quadro geral das jazidas lateríticas brasileiras de níquel. Como reflexo das condições tectônicas (que favoreceram a maior proteção do relevo) e climáticas (úmidas, mas não muito quentes), o perfil de alteração recente não é muito evoluído e é capeado por uma cobertura silicosa e ferruginosa muito espessa (20 m em média). 0 baixo grau de lateritização explica os baixos teores de níquel e a fraca espessura de minério. As coberturas parcialmente herdadas de outro ciclo tornam anti-econômica a lavra de vários setores da jazida. Apesar de certas zonas de saprólito ferruginoso silicificado apresentarem teores de $\mathrm{Ni}$ ao redor de $1 \%$, o alto teor de sílica prejudica o minério. $\mathrm{E}$ até os saprólitos argilosos ou grossos podem ser enriquecidos em sílica lixiviada do silcrete sobreposto. Apenas a parte mais oriental do maciço parece um pouco mais interessante economicamente. Nesta zona mais erodida, onde a antiga superfície é recortada em morrotes meia-laranja, as coberturas, tanto a ferruginosa como a silicosa, são menos espessas. Sua posição a jusante na paisagem (antiga como atual, como mostram os mergulhos do silcrete, da frente de alteração) e a direção geral dos rios deve explicar o melhor volume mineralizado: essa zona oriental acolheu provavelmente uma parte do níquel lixiviado de montante, através de transferência lateral. Com efeito, transferências laterais são quase sempre imprescindíveis para uma acumulação laterítica de $\mathrm{Ni}$ chegar ao nível econômico. Deste ponto de vista, os setores realmente mais interessantes da jazida seriam os flancos dos morrotes meia-laranja, que, no entanto, não representam uma grande reserva de minério.

Agradecimentos Os autores agradecem ao Prof. Dr. Helmut Born que os acompanhou, em 1978, na primeira visita à jazida, e à Serrana S.A. Mineração que gentilmente permitiu que os testemunhos de sondagem fossem amostrados.
ALMEIDA, F.F.M. de - 1983 - Relações tectônicas das rochas alcalinas mesozóicas na região meridional da Plataforma SulAmericana. Rev. Bras. Geoc. 13 (3) :139-158.

BAUER, H.E. - 1890 - As minas de Iporanga. Rev. Eng. 232 : 85-87.

BERNADELLI, A.; MELFI, A.J.; OLIVEIRA, S.M.B. de; TRESCASES, J.J. - 1982 - The Carajás nickel deposit. It Int. Symp. Lat. Proc. : 107-118.

BRINDLEY, G.W. - 1978 - The structure and chemistry of hydrous nickel - containing silicate and aluminate minerals, Bull. $B R G M$, sect. II, $3: 233-245$.

DERBY, O.A. - 1981 - On the magnetite ore districts of Jacupiranga and Ipanema - Am. Sc. Serv. 41: 311-321.

DINO, R. - 1984 - Gênese do minério de níquel de São João do Piaut por alteração intempérica. São Paulo, IG-USP. 142 p. (Dissertação de mestrado, inédita).

FELICISSIMO Jr., J. - 1968 - Distritos ultrabásico-alcalinos da bacia tectônica do Baixo Ribeira e seus aspectos econômicos, Estado de São Paulo. Sem. Est. Geol. Ouro Preto, MG, 4 : 90-134.

KING, L.C. - 1956 - A geomorfologia do Brasil oriental. Rev. Bras. Geogr. 2 :147-265.

LELONG, F.; TARDY, Y.; GRANDIN, G; TRESCASES, J.J.; BOULANGÉ, B. - 1976 - Pedogenesis, chemical weathering and processes of formation of some supergene ore deposits. In: Wolf., R.H. (ed.), Elsevier, v. 3, p. 92-173.

MELCHER, G.C. - 1954 - Nota sobre o distrito alcalino de Jacupiranga,Estado de São Paulo. DNPM/DGM, Notas Prel., 84 p.
MELFI, A.J.; SOUZA, A. de; SINELLI, O.; GONÇALVES, N.M. 1970 - Ocorrência de feldspatos niquelíferos em Niquelândia, GO. In: CONGR. BRAS. GEOL., 24, Brasília, 1970. Anais... Brasília, SBG, p. 245-248.

MELFI, A.J.; TRESCASES, J.J.; OLIVEIRA, S.M.B. de - $1980-$ Les "laterites" nickélifères du Brésil. Cah. ORSTOM, Sér. Geol., 11 (1): 15-42.

MORGENTAL, A.; BATOLLA Jr., F.; PINTO, G.G.; PAIVA, I.P.; DRUMOND, J.B.V. - 1975 - Projeto Sudelpa: Relatório Final. Geologia, v. 1, 707 p.

OLIVEIRA, S.M.B. de \& TRESCASES, J.J. - 1980 - Geoquímica da alteração supérgena das rochas ultramáficas de Sta. Fé (Goiás-Brasil). Rev. Bras. Geoc. 10 : 243-257.

PONÇANO, W.L.; CARNEIRO, C.D.R.; BISTRICHI, C.A.; ALMEIDA, F.F.M. de; PRANDINI, F.L. - 1981 - Mapa geomorfológico do Estado de São Paulo. São Paulo, IPT, 94 p. (Monografias 5).

RAMALHO, R. \& HANSEN, I.E.P. - 1975 - Projeto Sudelpa: relatório final. Geomorfologia, V. XII, $105 \mathrm{p}$.

TRESCASES, J.J. \& OLIVEIRA, S.M.B. de - 1978 - Alteração dos serpentinitos de Morro do Níquel (MG). In: CONGR. BRAS. GEOL., 30, Recife, 1978. Anais..., Recife, SBG, v. 4, p. 1655-1669.

ULBRICH, H.H.G.J. \& GOMES, C. de B. - 1981 - Alkaline rocks from continental Brazil. Earth Sci. Rev. 17 : 135-154.

MANUSCRITO

Recebido em 16 de setembro de 1985 Revisão aceita em 29 de novembro de 1985 